Article

\title{
Anti-Inflammatory and Neuroprotective Constituents from the Peels of Citrus grandis
}

\author{
Ping-Chung Kuo ${ }^{1,+}$, Yu-Ren Liao ${ }^{1,+}{ }^{+}$Hsin-Yi Hung ${ }^{1,+}$, Chia-Wei Chuang ${ }^{2}$, \\ Tsong-Long Hwang ${ }^{3,4,5}$, Shiow-Chyn Huang ${ }^{6}$, Young-Ji Shiao ${ }^{7}$, Daih-Huang Kuo ${ }^{8}$ and \\ Tian-Shung $\mathrm{Wu}^{1,8, *}$ \\ 1 School of Pharmacy, College of Medicine, National Cheng Kung University, Tainan 701, Taiwan; \\ z10502016@email.ncku.edu.tw (P.-C.K.); truthloveroy@yahoo.com.tw (Y.-R.L.); \\ z10308005@email.ncku.edu.tw (H.-Y.H.) \\ 2 Department of Chemistry, National Cheng Kung University, Tainan 701, Taiwan; w96s062001@hotmail.com \\ 3 Graduate Institute of Natural Products, College of Medicine, Chang Gung University, Taoyuan 333, Taiwan; \\ htl@mail.cgu.edu.tw \\ 4 Research Center for Chinese Herbal Medicine, Research Center for Food and Cosmetic Safety, \\ and Graduate Institute of Health Industry Technology, College of Human Ecology, \\ Chang Gung University of Science and Technology, Taoyuan 333, Taiwan \\ 5 Department of Anesthesiology, Chang Gung Memorial Hospital, Taoyuan 333, Taiwan \\ 6 Department of Pharmacy, Chia-Nan University of Pharmacy and Science, Tainan 717, Taiwan; \\ schuang@mail.cnu.edu.tw \\ 7 Division of Basic Chinese Medicine, National Research Institute of Chinese Medicine, \\ Ministry of Health and Welfare, Taipei 112, Taiwan; yshiao@nricm.edu.tw \\ 8 Department of Pharmacy, College of Pharmacy and Health Care, Tajen University, Pingtung 907, Taiwan; \\ dhkou@tajen.edu.tw \\ * Correspondence: tswu@mail.ncku.edu.tw; Tel.:+886-6274-7538 \\ + These authors contributed equally to this work.
}

Academic Editor: Thomas J. Schmidt

Received: 19 April 2017; Accepted: 8 June 2017; Published: 9 June 2017

\begin{abstract}
A series of chromatographic separations performed on the ethanol extracts of the peels of Citrus grandis has led to the characterization of forty compounds, including seventeen coumarins, eight flavonoids, two triterpenoids, four benzenoids, two steroids, one lignan, one amide, and five other compounds, respectively. The chemical structures of the purified constituents were identified on the basis of spectroscopic elucidation, including 1D- and 2D-NMR, UV, IR, and mass spectrometric analysis. Most of the isolated compounds were examined for their inhibition of superoxide anion generation and elastase release by human neutrophils. Among the isolates, isomeranzin (3), 17,18-dihydroxybergamottin (12), epoxybergamottin (13), rhoifolin (19), vitexicarpin (22) and 4-hydroxybenzaldehyde (29) displayed the most significant inhibition of superoxide anion generation and elastase release with $\mathrm{IC}_{50}$ values ranged from 0.54 to $7.57 \mu \mathrm{M}$, and 0.43 to $4.33 \mu \mathrm{M}$, respectively. In addition, 7-hydroxy-8-(2'-hydroxy-3'-methylbut-3'-enyl)coumarin (8) and 17,18-dihydroxybergamottin (12) also exhibited the protection of neurons against $A \beta$-mediated neurotoxicity at $50 \mu \mathrm{M}$.
\end{abstract}

Keywords: Citrus grandis; chromatographic method; spectroscopic elucidation; superoxide anion generation; elastase release; neuroprotective

\section{Introduction}

The genus Citrus is composed of various species grown all over the tropical and subtropical regions. Each species has its own characteristic aroma and some Citrus peel oils have been used 
in a variety of products such as foods, beverages and perfumes [1]. A lot of scientific reports have been published regarding the compositions and significant bioactivity of the Citrus peels. C. grandis belongs to the family Rutaceae, which is cultivated throughout Taiwan, Indochina, and Southern China [2-11]. The peels of mature fruits of $C$. grandis have been used in traditional Chinese medicine for treating the common cold and cancer, and relieving exhaustion [12]. Many natural products such as flavonoids, coumarins, and terpenoids have been isolated from C. grandis [2-11]. Among these, various principles have been reported to exhibit antioxidant [13-16], anti-inflammatory [16-20], anti-microbial [21-24], and anti-cancer effects [25-28]. In addition, several compounds were subjected to the study related to the prevention of vascular diseases [29-32]. The constituents of the peels of C. grandis were found to be rich in coumarins and flavonoids. The substitution of multi-methoxyl group of flavonoids, polymethoxyflavones (PMFs) were found to be rich in Citrus which have been reported to exhibit antioxidant because of the delocalized electrons [33]. That is why the Citrus genus is an important food source for people, and it was also an important Chinese medicine from ancient times. In a previous study [34], Citrus flavonoids were reported to exhibit anti-inflammatory and neuroprotective bioactivities. Therefore, in the present study we wish to explore other bioactive principles of peels of $C$. grandis.

\section{Results and Discussion}

The dried peels of $C$. grandis were extracted with $\mathrm{EtOH}$ and the resulting extract was then filtered and concentrated. The EtOH extracts were suspended in distilled water and successively partitioned with EtOAc to afford EtOAc layer and water layer, respectively. A sequential combination of conventional chromatographic techniques was utilized to isolate the constituents described below. Totally 40 known compounds were isolated and identified, including seventeen coumarins (7-geranyloxycoumarin (1) [35], osthenol (2) [36], isomeranzin (3) [37], marmin (4) [37], epoxyaurapten (5) [38], meranzin hydrate (6) [39], hopeyhopin (7) [40], 7-hydroxy-8- (2'-hydroxy-3'methylbut-3'-enyl)coumarin (8) [37], isoimperatorin (9) [41], bergamottin (10) [42], bergaptol (11) [43], 17,18-dihydroxybergamottin (12) [44], epoxybergamottin (13) [45], auraptenol (14) [39], columbianetin (15) [36], yuehgesin-C (16) [46], bergomottin (17) [47]); eight flavonoids (naringin (18) [48], rhoifolin (19) [49], naringenin 7-rutinoside (20) [50], melitidin (21) [51], vitexicarpin (22) [52], chrysosplin (23) [53], 5-hydroxy-3,6,7,3', 4'-pentamethoxyflavone (24) [54], rubranonoside (25) [55]); two triterpenoids, friedelin (26) [56] and limonin (27) [48]; four benzenoids (eleutheroside B (28) [57], 4-hydroxy-benzaldehyde (29) [58], phlorin (30) [59], methyl 4-hydroxybenzoate (31) [58]); two steroids ( $\beta$-sitosterol (32) [58], and $\beta$-sitosterol-3-O- $\beta$-D-glucopyranoside (33) [58]); one lignan, syringaresinol (34) [60]; one amide, 2-hydroxybenzoic acid N-2-(4-hydroxyphenyl)ethylamide (35) [61]; and five others compounds (octadecatrienoic acid (36) [62], myo-inositol (37) [63], scyllo-inositol (38) [63], 1-methoxy- $\beta$-carboline (39) [64], and adenosine (40) [65]), respectively. These compounds were subjected to spectroscopic elucidation, including UV, IR, 1D- and 2D-NMR data, along with the mass spectrometric analysis and their structures were identified by comparison of their physical and spectroscopic data with values reported in the literature.

Most of the purified compounds were examined for their inhibition of superoxide anion generation and elastase release by human neutrophils in response to $\mathrm{N}$-formyl-L-methionyl-phenylalanine/ cytochalasin B (fMLP/CB) [66,67]. Only compounds 3, 12, 13, 19, 22, and 29 (Figure 1) displayed inhibition percentages greater than $50 \%$ at the test concentration of $10 \mu \mathrm{M}$ and in the concentration range used these compounds displayed inhibitory effects in a dose-dependent manner. Compounds 3 , $12,13,19,22$, and 29 all displayed inhibition of superoxide anion generation with $\mathrm{IC}_{50}$ values ranging from $0.54 \pm 0.24$ to $7.57 \pm 3.19 \mu \mathrm{M}$, compared to the reference compound sorafenib [66] $\left(\mathrm{IC}_{50}\right.$ values of $1.49 \pm 0.42 \mu \mathrm{M}$, Table 1). In addition, compounds 3, 13, and 29 also exhibited inhibitory effects on elastase release, with $\mathrm{IC}_{50}$ values ranging from $0.43 \pm 0.09$ to $4.33 \pm 0.83 \mu \mathrm{M}$, compared to the reference compound sorafenib [66] ( $\mathrm{IC}_{50}$ values of $0.93 \pm 0.10 \mu \mathrm{M}$, Table 1). 
In the primary screening of the neuroprotective activity of the isolated compounds, $50 \mu \mathrm{M}$ of the compound was used. Alternatively, $10 \mu \mathrm{M}$ of the compound was used as this compound possessed neurotoxicity at $20 \mu \mathrm{M}$ (Figure 2A) [68]. The results showed that 7-hydroxy-8-(2'-hydroxy-3'methylbut-3'-enyl)coumarin (8) and 17,18-dihydroxybergamottin (12) (Figure 1) protected neurons against $\mathrm{A} \beta$-mediated neurotoxicity. The concentration dependency of neurons protection was further examined for compounds $\mathbf{8}$ and $\mathbf{1 2}$ and the experimental results displayed a dose-dependent manner as shown in Figure 2B,C.<smiles>COc1ccc2ccc(=O)oc2c1CC(=O)C(C)C</smiles><smiles>C/C(=C\COc1c2ccoc2cc2oc(=O)ccc12)CCC[C@H]1OC1(C)C</smiles>

13<smiles>C/C(=C\COc1ccc2ccc(=O)oc2c1)CC[C@@H](O)C(C)(C)O</smiles>

8<smiles>C/C(=C\COc1c2ccoc2cc2oc(=O)ccc12)CC[C@H](O)C(C)(C)O</smiles><smiles>C[C@@H]1O[C@H](O[C@H]2[C@@H](Oc3cc(O)c4c(=O)cc(-c5ccc(O)cc5)oc4c3)O[C@H](CO)[C@@H](O)[C@H]2O)[C@H](O)[C@@H](O)[C@H]1O</smiles>

19<smiles>COc1ccc(C2Oc3cc(OC)c(OC)c(O)c3C(=O)C2OC)cc1O</smiles>

22<smiles>O=Cc1ccc(O)cc1</smiles>

29

Figure 1. Structures of compounds 3, 8, 12, 13, 19, 22, and 29.

Table 1. Inhibitory effects of isolated compounds on superoxide anion generation and elastase release by human neutrophils in response to fMLP/CB.

\begin{tabular}{ccc}
\hline \multirow{2}{*}{ Compound } & Superoxide Anion Generation & Elastase Release \\
\cline { 2 - 3 } & $\mathbf{I C}_{\mathbf{5 0}}(\boldsymbol{\mu} \mathbf{M})^{\mathbf{a}}$ & $\mathbf{I C}_{\mathbf{5 0}}(\boldsymbol{\mu M})^{\mathbf{a}}$ \\
\hline $\mathbf{3}$ & $3.89 \pm 0.45^{* * *}$ & $4.33 \pm 0.83^{* * *}$ \\
$\mathbf{1 2}$ & $6.02 \pm 2.46^{* * *}$ & $>10$ \\
$\mathbf{1 3}$ & $7.57 \pm 3.19^{* * *}$ & $3.58 \pm 1.90^{* * *}$ \\
$\mathbf{1 9}$ & $3.79 \pm 0.42^{* * *}$ & $>10$ \\
$\mathbf{2 2}$ & $5.95 \pm 1.56^{* * *}$ & $>10$ \\
$\mathbf{2 9}$ & $0.54 \pm 0.24^{* * *}$ & $0.43 \pm 0.09^{* * *}$ \\
Sorafenib $^{\mathrm{b}}$ & $1.49 \pm 0.42^{*}$ & $0.93 \pm 0.10$
\end{tabular}

a Concentration necessary for $50 \%$ inhibition $\left(\mathrm{IC}_{50}\right)$. Results are presented as means $\pm \mathrm{SD}$. $(n=3 \sim 5) .{ }^{* * *} p<0.001$ compared with the control value. ${ }^{b}$ Sorafenib, a tyrosine kinase inhibitor, was used as a positive control.

The present experimental data suggest that the extracts and purified compounds of the peel of C. grandis have the potential to be developed as novel anti-inflammatory lead drugs or health foods. In addition, some purified constituents also exhibited the protection of neurons against $A \beta$-mediated neurotoxicity. It merits further investigations of the anti-inflammatory and neuroprotective mechanism of these natural heterocyclic compounds. 


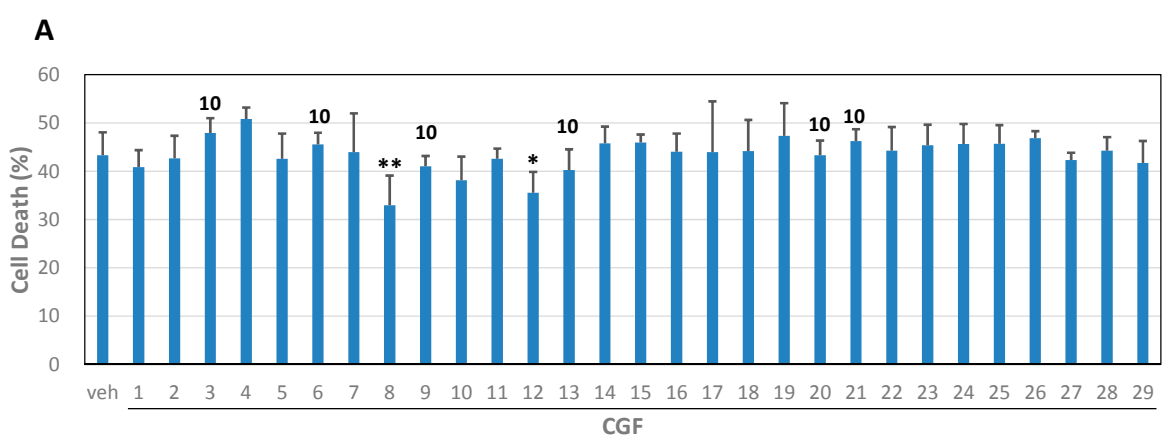

B

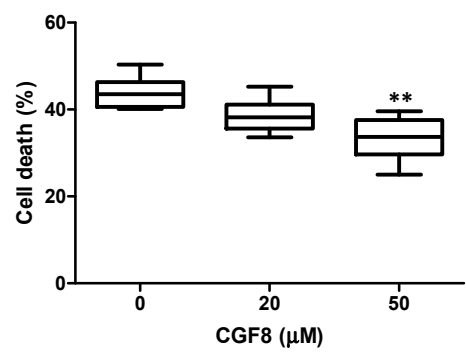<smiles>C/C(=C\COC1C=c2oc(=O)ccc2=CC1)CC[C@@H](O)C(C)(C)O</smiles>

C

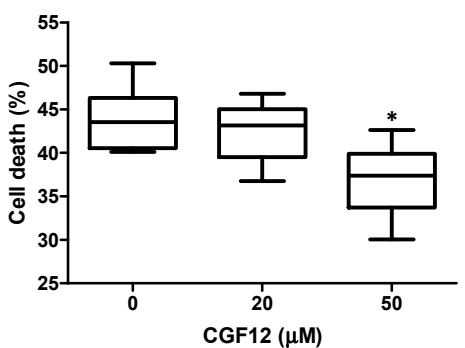<smiles>C/C(=C\COc1c2ccoc2cc2oc(=O)ccc12)CC[C@H](O)C(C)(C)O</smiles>

Figure 2. Compounds 8 and 12 protect cortical neurons against $A \beta-(25-35)-$ mediated neurotoxicity. Cortical neurons were pretreated with $50 \mu \mathrm{M}$ of compounds (or $10 \mu \mathrm{M}$ for those indicated as 10 above column). (A), or various concentration of compounds 8 (B) and 12 (C) for $2 \mathrm{~h}$ and then exposed to $10 \mu \mathrm{M}$ of $\mathrm{A} \beta-(25-35)$ for $40 \mathrm{~h}$. Cell viability was measured by MTT reduction assay. Results are means \pm S.D. from six independent experiments and expressed relative to control and plotted as box plot for showing the normal distribution. Significant differences between cells treated with A $\beta-(25-35)$ plus vehicle (veh) and $\mathrm{A} \beta-(25-35)$ plus compounds are indicated by ${ }^{*}, p<0.05 ;{ }^{* *}, p<0.01$.

\section{Materials and Methods}

\subsection{General Information}

Melting points were determined using an MP-S3 apparatus (Yanaco, Tokyo, Japan). UV spectra were recorded at room temperature on a U-0080-D spectrophotometer (Hitachi, Tokyo, Japan). IR spectra were obtained with a FT-IR Spectrum RX I spectrophotometer (PerkinElmer, Waltham, MA, USA). Optical rotations were measured using a P-2000 digital polarimeter (JASCO, Tokyo, Japan). ${ }^{1} \mathrm{H}$ - and ${ }^{13} \mathrm{C}-\mathrm{NMR}$ spectra were recorded on Avance III HD 700 and Avance III $400 \mathrm{NMR}$ spectrometers (Bruker, Billerica, MA, USA). Chemical shifts are shown in $\delta$ values (ppm) with tetramethylsilane as an internal standard. The ESIMS and HRESIMS were taken on a Bruker Daltonics APEX II 30e spectrometer (positive-ion mode). Column chromatography (CC) was performed on silica (70-230 mesh and 230-400 mesh, Merck, Darmstadt, Germany), Diaion HP-20 (Mitsubishi, Tokyo, Japan), and $\mathrm{C}_{18}$ (Sigma-Aldrich, St. Louis, MO, USA) gels, respectively, and preparative TLC (thin-layer chromatography) was conducted on Merck precoated silica gel 60 F254 plates, using UV light to visualize the spots. High-performance liquid chromatography (HPLC) was performed on an LC-20AT series pumping system (Shimadzu, Kyoto, Japan) equipped with a Shimadzu SPD-20A UV-vis detector, and a SIL-10AF auto-sampling system at ambient temperature. 


\subsection{Materials}

The peels of C. grandis were bought from the market in Tainan, Taiwan in 2010 and identified by Prof. Chang-Sheng Kuoh, Department of Life Science, National Cheng Kung University (NCKU), Tainan, Taiwan. A voucher specimen (Wu-2010009) was stored in School of Pharmacy, NCKU.

\subsection{Extraction and Isolation}

The dried peels of $C$. grandis $(1.0 \mathrm{~kg})$ were pre-treated with $\mathrm{EtOH}$ for one day at room temperature and then extracted with $95 \% \mathrm{EtOH}$ five times $(10 \mathrm{~L} \times 5 \mathrm{~h})$ at room temperature. The resulting extract was then filtered and concentrated in vacuo to yield a crude extract. The EtOH extract $(260 \mathrm{~g})$ was suspended in distilled water and successively partitioned with EtOAc yielding an EtOAc layer $(20 \mathrm{~g})$ and water layer $(240 \mathrm{~g})$. The EtOAc-soluble fraction was subjected to silica gel CC using a gradient solvent system of $n$-hexane-acetone (8:1, 4:1, 1:1 and MeOH) to afford ten fractions (F1 F10) according to TLC monitoring. Recrystallization of water layer produced the solids myo-inositol (37) (10.3 mg) and scyllo-inositol (38) (8.2 mg). The mother liquid of water layer was applied to CC on Diaion HP-20 gel using a gradient of increasing $\mathrm{MeOH}$ in $\mathrm{H}_{2} \mathrm{O}$ to yield eight fractions (W1 W8).

Fractions F1 and F2 were combined and isolated by CC on silica gel with a step gradient with $n$-hexane and diisopropyl ether mixtures (11:1, 9:1, 5:1, 2:1, 1:1, 0:1) to afford three subfractions (F1-1 F1-3). F1-2 was further purified by silica gel CC and recrystallization to obtain friedelin (26) (10.3 mg). Fractions F3 and F4 were combined and performed silica gel CC with gradient mixtures of $n$-hexane and ethyl acetate to produce five subfractions (F3-1 F3-5). F3-2 was purified by silica gel CC by gradient elution of $n$-hexane and ethyl acetate to afford several additional fractions. Further purification by TLC using $n$-hexane-ethyl acetate $(9: 1)$ and recrystallization yielded isoimperatorin (9) (16.7 mg) and $\beta$-sitosterol (32) (265.7 mg). F3-4 was further purified by silica gel CC and recrystallization to obtain bergomottin (17) $(2.5 \mathrm{mg})$ and octadecatrienoic acid (36) (10.4 mg).

Fraction F5 was subjected to silica gel CC with diisopropyl ether as eluent to afford six subfractions (F5-1 F5-6). F5-2 was purified by silica gel CC eluted by a gradient of $n$-hexane and diisopropyl ether to afford several minor fractions. Further purification by TLC using $n$-hexane and diisopropyl ether (3:1) and recrystallization yielded osthenol (2) (2.6 mg), isomeranzin (3) (3.2 mg), marmin (4) (1.1 mg), and 7-hydroxy-8-(2'-hydroxy-3'-methylbut-3'-enyl)coumarin (8) $(2.5 \mathrm{mg})$. Recrystallization of minor fractions of F5-4 produced yuehgesin-C (16) (302.2 mg). F5-5 was subjected to silica gel CC eluted with a gradient of $n$-hexane and ethyl acetate to afford three subfractions (F5-5-1 F5-5-3). F5-5-2 was further isolated by silica gel CC, eluted with $n$-hexane-isopropyl ether (2:1) and subsequent preparative TLC using $n$-hexane-acetone (9:1) or recrystallization of the minor fractions to afford epoxybergamottin (13) (1.0 mg), columbianetin (15) (6.6 mg), and 5-hydroxy-3,6,7,3', $4^{\prime}$-pentamethoxyflavone (24) (1.3 $\mathrm{mg})$, respectively.

Fraction F7 was purified by silica gel CC eluted by a mixture of chloroform and acetone (9:1) to yield six subfractions (F7-1 F7-6). Recrystallization of subfractions F7-1 to F7-4 produced limonin (27) (98.3 mg), bergaptol (11) (7.0 mg), 17,18-dihydroxybergamottin (12) (22.2 mg), auraptenol (14) (13.5 $\mathrm{mg}$ ), respectively. F7-5 was isolated on silica gel CC by gradient elution with $n$-hexane and acetone to afford several minor fractions. Further purification by TLC using chloroform and acetone (5:1) and recrystallization yielded vitexicarpin (22) $(6.2 \mathrm{mg})$ and chrysosplin (23) (3.2 $\mathrm{mg})$. Recrystallization of minor fractions of F7-6 produced $\mathrm{N}$-[8'-(4'-hydroxyphenylethyl)]-2-hydroxy-benzoylamide (35) (4.0 $\mathrm{mg})$.

Fractions F8 and F9 were combined and isolated by silica gel CC using a mixture of diisopropyl ether and ethyl acetate (1:1) to result in three subfractions (F8-1 F8-3). F8-2 was purified by silica gel $\mathrm{CC}$ with gradient elution using diisopropyl ether and ethyl acetate to afford several minor fractions. Further purification by TLC using diisopropyl ether and acetone (3:1) and recrystallization yielded meranzin hydrate (6) (2.8 mg), methyl 4-hydroxybenzoate (31) (2.1 mg), and syringaresinol (34) (1.9 mg).

Fractions W2 and W3 were combined and purified using $\mathrm{C}_{18}$ gel CC eluted with a gradient of $\mathrm{H}_{2} \mathrm{O}$ and $\mathrm{MeOH}(1: 0,9: 1,5: 1,2: 1,1: 1,0: 1)$ to afford three subfractions (W2-1 W2-3). W2-3 was isolated 
by HPLC with an Agilent semi-preparative RP-18 column $(21.2 \mathrm{~mm} \times 250 \mathrm{~mm})$ eluted with $\mathrm{H}_{2} \mathrm{O}$ and $\mathrm{MeOH}$ (60:40) to afford melitidin (21) (42.9 mg) and rubranonoside (25) (3.8 mg).

Fraction W4 was subjected to $\mathrm{C}_{18}$ gel CC eluted with a gradient of $\mathrm{H}_{2} \mathrm{O}$ and $\mathrm{MeOH}$ to yield five subfractions (W4-1 W4-5). W4-2 was subjected to HPLC with an Agilent analytical RP-18 column (4.6 mm $\times 250 \mathrm{~mm}$ ) eluted with $\mathrm{H}_{2} \mathrm{O}$ and $\mathrm{MeOH}$ (55:45) to furnish rhoifolin (19) (3.4 mg) and naringenin 7-rutinoside (20) (3.0 mg). W4-3 was isolated by $\mathrm{C}_{18}$ gel CC with gradient mixtures of $\mathrm{H}_{2} \mathrm{O}$ and $\mathrm{MeOH}$ to afford several minor fractions. W4-3-2 was purified by HPLC on an Agilent analytical RP-18 column ( $4.6 \mathrm{~mm} \times 250 \mathrm{~mm}$ ) eluted with $\mathrm{H}_{2} \mathrm{O}$ and $\mathrm{MeOH}$ (70:30) to yield hopeyhopin (7) $(3.8 \mathrm{mg})$ and eleutheroside B (28) $(1.8 \mathrm{mg})$. Recrystallization of minor fractions of W4-4 resulted in adenosine (40) (13.9 mg).

Fractions W5 and W6 were combined and purified using $\mathrm{C}_{18}$ gel CC eluted with mixtures of $\mathrm{H}_{2} \mathrm{O}$ and $\mathrm{MeOH}$ to afford four subfractions (W5-1 W5-4). Recrystallization of subfraction W5-1 produced naringin (18) (440.0 mg). W5-2 was isolated by $\mathrm{C}_{18}$ gel CC with gradient mixtures of $\mathrm{H}_{2} \mathrm{O}$ and $\mathrm{MeOH}$ to afford phlorin (30) (26.3 mg). W5-3 was purified by HPLC on an Agilent analytical RP-18 column (4.6 mm $\times 250 \mathrm{~mm}$ ) eluted with $\mathrm{H}_{2} \mathrm{O}$ and $\mathrm{MeOH}$ (65:35) to yield epoxyaurapten (5) (1.0 mg) and 1-methoxy- $\beta$-carboline (39) (1.0 mg).

Fraction W7 was subjected to $\mathrm{C}_{18}$ gel $\mathrm{CC}$ with gradient elution using $\mathrm{H}_{2} \mathrm{O}$ and $\mathrm{MeOH}$ to provide three subfractions (W7-1 W7-3). Recrystallization of subfractions W7-1 and W7-2 produced $\beta$-sitosterol-3-O- $\beta$-D-glucopyranoside (33) $(11.6 \mathrm{mg}$ ) and 7-geranyloxycoumarin (1) $(4.0 \mathrm{mg})$, respectively. Further purification of W7-3 by preparative TLC using chloroform and acetone (5:1) and recrystallization yielded 4-hydroxybenzaldehyde (29) $(1.9 \mathrm{mg})$.

\subsection{Bioactivity Examination}

\subsubsection{Preparation of Human Neutrophils}

A study involving human neutrophils was approved by the Institutional Review Board at Chang Gung Memorial Hospital, Taoyuan, Taiwan, and was conducted according to the Declaration of Helsinki (2013). The written informed consent was obtained from each healthy donor before blood was drawn. Blood was drawn from healthy human donors (20-30 years old) by venipuncture into heparin-coated vacutainer tubes, using a protocol approved by the Institutional Review Board at Chang Gung Memorial Hospital. Blood samples were mixed gently with an equal volume of 3\% dextran solution. Neutrophils were isolated with a standard method of dextran sedimentation prior to centrifugation in a Ficoll Hypaque gradient and hypotonic lysis of erythrocytes. The leukocyte-rich plasma was collected after sedimentation of the red cells for $30 \mathrm{~min}$ at room temperature, and was transferred to $20 \mathrm{~mL}$ Ficoll solution $(1.077 \mathrm{~g} / \mathrm{mL})$ and spun down at $400 \mathrm{~g}$ for $40 \mathrm{~min}$ at $20^{\circ} \mathrm{C}$. The granulocyte/erythrocyte pellets were resuspended in ice-cold $0.2 \% \mathrm{NaCl}$ to lyse erythrocytes. After $30 \mathrm{~s}$, the same volume of $1.6 \% \mathrm{NaCl}$ solution was added to reconstitute the isotonic condition. Purified neutrophils were pelleted and then resuspended in a calcium $\left(\mathrm{Ca}^{2+}\right)$-free Hank's balanced salt solution (HBSS) buffer at $\mathrm{pH} 7.4$, and were maintained at $4{ }^{\circ} \mathrm{C}$ before use.

\subsubsection{Inhibition of Superoxide Anion Generation}

The assay of the generation of superoxide anion was based on the SOD-inhibitable reduction of ferricytochrome c $[65,66]$. In brief, after supplementation with $0.5 \mathrm{mg} / \mathrm{mL}$ ferricytochrome $\mathrm{c}$ and $1 \mathrm{mM} \mathrm{Ca}^{2+}$, neutrophils $\left(6 \times 10^{5}\right.$ cells $\left./ \mathrm{mL}\right)$ were equilibrated at $37^{\circ} \mathrm{C}$ for $2 \mathrm{~min}$ and incubated with drugs or an equal volume of vehicle (0.1\% DMSO, negative control) for $5 \mathrm{~min}$. Cells were activated with $100 \mathrm{nM}$ fMLP during the preincubation of $1 \mu \mathrm{g} / \mathrm{mL}$ cytochalasin B (fMLP/CB) for $3 \mathrm{~min}$. Changes in the absorbance with a reduction in ferricytochrome $\mathrm{c}$ at $550 \mathrm{~nm}$ were continuously monitored in a double-beam, six-cell positioner spectrophotometer with constant stirring (Hitachi U-3010). Calculations were based on differences in the reactions with and without SOD $(100 \mathrm{U} / \mathrm{mL})$ 
divided by the extinction coefficient for the reduction of ferricytochrome $\mathrm{c}(\varepsilon=21.1 / \mathrm{mM} / 10 \mathrm{~mm}$ at the concentration of $1 \mathrm{mM}$ in cuvette with 1-cm optical path length).

\subsubsection{Inhibition of Elastase Release}

Degranulation of azurophilic granules was determined by elastase release as described previously [65,66]. Experiments were performed using MeO-Suc-Ala-Ala-Pro-Val-p-nitroanilide as the elastase substrate. Briefly, after supplementation with MeO-Suc-Ala-Ala-Pro-Val- $p$-nitroanilide $(100 \mu \mathrm{M})$, neutrophils $\left(6 \times 10^{5} / \mathrm{mL}\right)$ were equilibrated at $37^{\circ} \mathrm{C}$ for $2 \mathrm{~min}$ and incubated with test compounds or an equal volume of vehicle (0.1\% DMSO, negative control) for $5 \mathrm{~min}$. Cells were activated by $100 \mathrm{nM}$ fMLP and $0.5 \mu \mathrm{g} / \mathrm{mL}$ cytochalasin B, and changes in absorbance at $405 \mathrm{~nm}$ were continuously monitored to assay elastase release. The results were expressed as the percent of elastase release in the $\mathrm{fMLP} / \mathrm{CB}$-activated, drug-free control system.

\subsubsection{Statistical Analysis}

Normal distribution with Shapiro-Wilk was performed. The results are expressed as the mean \pm SD. and were analyzed by analysis of variance (ANOVA) with post-hoc Bonferroni multiple comparisons tests. Calculations of $50 \%$ inhibitory concentrations $\left(\mathrm{IC}_{50}\right)$ were computer-assisted (PHARM/PCS v.4.2). Statistical comparisons were made between groups using the Student's $t$ test. Values of $p$ less than 0.05 were considered to be statistically significant.

\subsubsection{Neuroprotective Activity}

Primary cultures of neonatal cortical neurons were prepared from the cerebral cortex of Harlan Sprague-Dawley rat pups at postnatal day 1 [67]. Briefly, each pup was decapitated and the cortex was digested in $0.5 \mathrm{mg} / \mathrm{mL}$ papain at $37^{\circ} \mathrm{C}$ for $15 \mathrm{~min}$. The tissue was dissociated in Hypernate A medium (containing B27 supplement) by aspirating trituration. Cells were plated $\left(5 \times 10^{4} \mathrm{cells} / \mathrm{cm}^{2}\right)$ onto poly-D-lysine-coated dishes and maintained in neurobasal medium containing B27 supplement, 10 units $/ \mathrm{mL}$ penicillin, $10 \mathrm{mg} / \mathrm{mL}$ streptomycin, and $0.5 \mathrm{mg} / \mathrm{mL}$ glutamine $\left(5 \% \mathrm{CO}_{2} / 9 \% \mathrm{O}_{2}\right)$ for 3 days. Cells were then exposed to cytosine- $\beta$-D-arabinofuranoside $(5 \mathrm{mM})$ for 1 day to inhibit proliferation of non-neuronal cells. The cells were used for the experiment on the fifth day. The reduction of MTT was used to evaluate the cell viability. Cells were incubated with minimum essential medium containing $0.5 \mathrm{mg} / \mathrm{mL}$ MTT for $1 \mathrm{~h}$. The medium was aspirated, and the formazan particle was dissolved with lysis buffer (10\% sodium dodecyl sulfate, $3.3 \mathrm{mM} \mathrm{HCl}, 50 \%$ dimethylformamide). A $600 \mathrm{~nm}$ absorbance was measured by using enzyme-linked immunosorbent assay reader. The results are expressed as the mean \pm SD and were analyzed by analysis of variance (ANOVA) with post-hoc Bonferroni multiple comparisons tests.

Acknowledgments: This study is sponsored by the Ministry of Science and Technology, Taiwan, granted to T.-S.W. Authors are also thankful to Chang Gung Memorial Hospital (CMRPD1B0281 3, CMRPF1D0442 3, CMRPF 1F0011 3, CMRPF1F0061 3 and BMRP450 granted to T.-L.H.) for the partial financial support for the present research.

Author Contributions: Ping-Chung Kuo, Yu-Ren Liao, Hsin-Yi Hung, and Chia-Wei Chuang performed the research and recorded the spectra. Tsong-Long Hwang had done most of the inhibition experiments on human neutrophils and Daih-Huang Kuo help to elucidate a part of the anti-inflammatory bioactivity. Young-Ji Shiao completed the neuroprotective bioactivity examination. Shiow-Chyn Huang and Yu-Ren Liao help to elucidate a part of the neuroprotective bioactivity. Tian-Shung $\mathrm{Wu}$ designed the research and provided the research outlines. Ping-Chung Kuo and Hsin-Yi Hung completed the manuscript draft. All authors read and approved the final manuscript.

Conflicts of Interest: The authors declare no conflict of interest. 


\section{References}

1. Rendeiro, C.; Dong, H.; Saunders, C.; Harkness, L.; Blaze, M.; Hou, Y.; Belanger, R.L.; Corona, G.; Lovegrove, J.A.; Spencer, J.P. Flavanone-rich Citrus beverages counteract the transient decline in postprandial endothelial function in humans: A randomised, controlled, double-masked, cross-over intervention study. Br. J. Nutr. 2016, 116, 1999-2010. [CrossRef] [PubMed]

2. Hattori, S.; Shimokoriyama, M.; Kanao, M. Studies on flavanone glycosides. IV. The glycosides of ripe fruit peel and flower petals of Citrus aurantium L. J. Am. Chem. Soc. 1952, 74, 3614-3615. [CrossRef]

3. Wu, T.S.; Kuoh, C.S.; Furukawa, H. Acridone alkaloids and a coumarin from Citrus grandis. Phytochemistry 1983, 22, 1493-1497.

4. McPhail, A.T.; Ju-ichi, M.; Fujitani, Y.; Inoue, M.; Wu, T.S.; Furukawa, H. Isolation and structures of citropone-A and -B from Citrus plants, first examples of naturally-occurring homoacridone alkaloids containing a tropone ring system. Tetrahedron Lett. 1985, 26, 3271-3272. [CrossRef]

5. Wu, T.S.; Huang, S.C.; Jong, T.T.; Lai, J.S.; Furukawa, H. Honyumine, a new linear pyranoacridone alkaloids from Citrus grandis Osbeck. Heterocycles 1986, 24, 41-43. [CrossRef]

6. Wu, T.S. Baiyumine-A and -B, two acridone alkaloids from Citrus grandis. Phytochemistry 1987, 26, 871-872. [CrossRef]

7. Wu, T.S.; Huang, S.C.; Jong, T.T.; Lai, J.S.; Kuoh, C.S. Coumarins, acridone alkaloids and a flavone from Citrus grandis. Phytochemistry 1988, 27, 585-587. [CrossRef]

8. Wu, T.S. Alkaloids and coumarins of Citrus grandis. Phytochemistry 1988, 27, 3717-3718. [CrossRef]

9. Huang, S.C.; Chen, M.T.; Wu, T.S. Alkaloids and coumarins from stem bark of Citrus grandis. Phytochemistry 1989, 28, 3574-3576. [CrossRef]

10. Wu, T.S.; Huang, S.C.; Lai, J.S. Stem bark coumarins of Citrus grandis. Phytochemistry 1994, 36, $217-219$.

11. Takemura, Y.; Ju-ichi, M.; Ito, C.; Furukawa, H.; Tokuda, H. Studies on the inhibitory effects of some acridone alkaloids on Epstein-Barr virus activation. Planta Med. 1995, 61, 366-368. [CrossRef] [PubMed]

12. Zhang, T.; Peng, S. Introduction to the origin and evolution of Pomelo and its distribution in China. Chin. J. Ecol. 2000, 19, 58-61.

13. Mokbel, M.S.; Hashinaga, F. Evaluation of the antioxidant activity of extracts from buntan (Citrus grandis Osbeck) fruit tissues. Food Chem. 2006, 94, 529-534. [CrossRef]

14. Tsai, H.L.; Chang, S.K.; Chang, S.J. Antioxidant content and free radical scavenging ability of fresh red pummelo [Citrus grandis (L.) Osbeck] juice and freeze-dried products. J. Agric. Food Chem. 2007, 55, 2867-2872. [CrossRef] [PubMed]

15. Kim, G.N.; Shin, J.G.; Jang, H.D. Antioxidant and antidiabetic activity of Dangyuja (Citrus grandis Osbeck) extract treated with Aspergillus saitoi. Food Chem. 2009, 117, 35-41. [CrossRef]

16. Parhiz, H.; Roohbakhsh, A.; Soltani, F.; Rezaee, R.; Iranshahi, M. Antioxidant and anti-inflammatory properties of the Citrus flavonoids hesperidin and hesperetin: An updated review of their molecular mechanisms and experimental models. Phytother. Res. 2015, 29, 323-331. [CrossRef] [PubMed]

17. La, V.D.; Zhao, L.; Epifano, F.; Genovese, S.; Grenier, D. Anti-inflammatory and wound healing potential of Citrus auraptene. J. Med. Food 2013, 16, 961-964. [CrossRef] [PubMed]

18. Impellizzeri, D.; Bruschetta, G.; Di Paola, R.; Ahmad, A.; Campolo, M.; Cuzzocrea, S.; Esposito, E.; Navarra, M. The anti-inflammatory and antioxidant effects of bergamot juice extract (BJe) in an experimental model of inflammatory bowel disease. Clin. Nutr. 2014, 33, 749-753. [CrossRef] [PubMed]

19. Mitoshi, M.; Kuriyama, I.; Nakayama, H.; Miyazato, H.; Sugimoto, K.; Kobayashi, Y.; Jippo, T.; Kuramochi, K.; Yoshida, H.; Mizushina, Y. Suppression of allergic and inflammatory responses by essential oils derived from herbal plants and Citrus fruits. Int. J. Mol. Med. 2014, 33, 1643-1651. [CrossRef] [PubMed]

20. Noh, H.J.; Hwang, D.; Lee, E.S.; Hyun, J.W.; Yi, P.H.; Kim, G.S.; Lee, S.E.; Pang, C.; Park, Y.J.; Chung, K.H.; et al. Anti-inflammatory activity of a new cyclic peptide, citrusin XI, isolated from the fruits of Citrus unshiu. J. Ethnopharmacol. 2015, 163, 106-112. [CrossRef] [PubMed]

21. Shende, S.; Ingle, A.P.; Gade, A.; Rai, M. Green synthesis of copper nanoparticles by Citrus medica Linn. (Idilimbu) juice and its antimicrobial activity. World J. Microbiol. Biotechnol. 2015, 31, 865-873. [CrossRef] [PubMed] 
22. Chubukov, V.; Mingardon, F.; Schackwitz, W.; Baidoo, E.E.; Alonso-Gutierrez, J.; Hu, Q.; Lee, T.S.; Keasling, J.D.; Mukhopadhyay, A. Acute limonene toxicity in Escherichia coli is caused by limonene hydroperoxide and alleviated by a point mutation in alkyl hydroperoxidase AhpC. Appl. Environ. Microbiol. 2015, 81, 4690-4696. [CrossRef] [PubMed]

23. Wu, M.C.; Li, H.C.; Wu, P.H.; Huang, P.H.; Wang, Y.T. Assessment of oligogalacturonide from Citrus pectin as a potential antibacterial agent against foodborne pathogens. J. Food Sci. 2014, 79, 1541-1544. [CrossRef] [PubMed]

24. Vollmerhausen, T.L.; Ramos, N.L.; Dzung, D.T.; Brauner, A. Decoctions from Citrus reticulata Blanco seeds protect the uroepithelium against Escherichia coli invasion. J. Ethnopharmacol. 2013, 150, 770-774. [CrossRef] [PubMed]

25. Roohbakhsh, A.; Parhiz, H.; Soltani, F.; Rezaee, R.; Iranshahi, M. Molecular mechanisms behind the biological effects of hesperidin and hesperetin for the prevention of cancer and cardiovascular diseases. Life Sci. 2015, 124, 64-74. [CrossRef] [PubMed]

26. Murthy, K.N.; Jayaprakasha, G.K.; Patil, B.S. Cytotoxicity of obacunone and obacunone glucoside in human prostate cancer cells involves Akt-mediated programmed cell death. Toxicology 2015, 329, 88-97. [CrossRef] [PubMed]

27. Leclere, L.; Fransolet, M.; Cote, F.; Cambier, P.; Arnould, T.; Van Cutsem, P.; Michiels, C. Heat-modified Citrus pectin induces apoptosis-like cell death and autophagy in HepG2 and A549 cancer cells. PLoS ONE 2015, 10, e0115831. [CrossRef] [PubMed]

28. Zeng, Z.Y.; Chen, Y.; Zou, L.; Zhang, Y.; Hu, F.; Feng, J.; Shen, J.; Wei, B. Naringin inhibits growth and induces apoptosis by a mechanism dependent on reduced activation of NF- $\mathrm{kB} / \mathrm{COX}-2$ caspase-1 pathway in HeLa cervical cancer cells. Int. J. Oncol. 2014, 45, 1929-1936. [CrossRef] [PubMed]

29. Razavi, B.M.; Arasteh, E.; Imenshahidi, M.; Iranshahi, M. Antihypertensive effect of auraptene, a monoterpene coumarin from the genus Citrus, upon chronic administration. Iran. J. Basic Med. Sci. 2015, 18, 153-158. [PubMed]

30. Orhan, I.E.; Nabavi, S.F.; Daglia, M.; Tenore, G.C.; Mansouri, K.; Nabavi, S.M. Naringenin and atherosclerosis: A review of literature. Curr. Pharm. Biotechnol. 2015, 16, 245-251. [CrossRef] [PubMed]

31. Liu, Y.; Niu, L.; Cui, L.; Hou, X.; Li, J.; Zhang, X.; Zhang, M. Hesperetin inhibits rat coronary constriction by inhibiting $\mathrm{Ca}^{2+}$ influx and enhancing voltage-gated $\mathrm{K}^{+}$channel currents of the myocytes. Eur. J. Pharmacol. 2014, 735, 193-201. [CrossRef] [PubMed]

32. Chanet, A.; Claude, S.; Maier, J.A.; Kamran, K.M.; Rakotomanomana, N.; Shinkaruk, S.; Bérard, A.M.; Bennetau, P.C.; Mazur, A.; Morand, C. Flavanone metabolites decrease monocyte adhesion to TNF- $\alpha$-activated endothelial cells by modulating expression of atherosclerosis-related genes. Br. J. Nutr. 2013, 110, 587-598. [CrossRef] [PubMed]

33. Wang, L.; Wang, J.; Fang, L.; Zheng, Z.; Zhi, D.; Wang, S.; Li, S.; Ho, C.T.; Zhao, H. Anticancer activities of citrus peel polymethoxyflavones related to angiogenesis and others. Biol. Med. Res. Int. 2014, 30, 453-463. [CrossRef] [PubMed]

34. Hwang, S.L.; Shih, P.H.; Yen, G.C. Neuroprotective effects of citrus flavonoids. J. Agric. Food Chem. 2012, 60, 877-885. [CrossRef] [PubMed]

35. Jun, M.; Bacay, A.F.; Moyer, J.; Webb, A.; Carrico-Moniz, D. Synthesis and biological evaluation of isoprenylated coumarins as potential anti-pancreatic cancer agents. Bioorg. Med. Chem. Lett. 2014, 24, 4654-4658. [CrossRef] [PubMed]

36. Beare, K.D.; McErlean, C.S.P. Accessing columbianetin-containing natural products via a domino on-water, in-water process. Tetrahedron Lett. 2013, 54, 1056-1058. [CrossRef]

37. Feger, W.; Brandauer, H.; Gabris, P.; Ziegler, H. Nonvolatiles of commercial lime and grapefruit oils separated by high-speed countercurrent chromatography. J. Agric. Food Chem. 2006, 54, 2242-2252. [CrossRef] [PubMed]

38. Francis Rouessac, M.A. Syntheses en serie racemique et en serie optiquement active d'une famille de derives oxygenes naturels de l'ombelliferone. Structure spatiale du (-) epoxy-3'6' auraptene. Tetrahedron 1988, 44, 101-110.

39. Cai, J.N.; Basnet, P.; Wang, Z.T.; Komatsu, K.; Xu, L.S.; Tani, T. Coumarins from the fruits of Cnidium monnieri. J. Nat. Prod. 2000, 63, 485-488. [CrossRef] [PubMed] 
40. Panthong, K.; Srisud, Y.; Rukachaisirikul, V.; Hutadilok-Towatana, N.; Voravuthikunchai, S.P.; Tewtrakul, S. Benzene, coumarin and quinolinone derivatives from roots of Citrus hystrix. Phytochemistry 2013, 88, 79-84. [CrossRef] [PubMed]

41. Znati, M.; Ben Jannet, H.; Cazaux, S.; Souchard, J.P.; Harzallah Skhiri, F.; Bouajila, J. Antioxidant, 5-lipoxygenase inhibitory and cytotoxic activities of compounds isolated from the Ferula lutea flowers. Molecules 2014, 19, 16959-16975. [CrossRef] [PubMed]

42. Marumoto, S.; Miyazawa, M. Structure-activity relationships for naturally occurring coumarins as beta-secretase inhibitor. Bioorg. Med. Chem. 2012, 20, 784-788. [CrossRef] [PubMed]

43. Esquivel-Ferrino, P.C.; Favela-Hernandez, J.M.; Garza-Gonzalez, E.; Waksman, N.; Rios, M.Y.; del Rayo Camacho-Corona, M. Antimycobacterial activity of constituents from Foeniculum vulgare var. dulce grown in Mexico. Molecules 2012, 17, 8471-8482. [PubMed]

44. Ohta, T.; Maruyama, T.; Nagahashi, M.; Miyamoti, Y.; Hosoi, S.; Kiuchi, F.; Yamazoe, Y.; Tsukamoto, S.; Paradisin, C. A new CYP3A4 inhibitor from grapefruit juice. Tetrahedron 2002, 58, 6631-6635. [CrossRef]

45. Abulrob, A.; Suller, M.T.E.; Gumbleton, M.; Simons, C.; Russell, A.D. Identification and biological evaluation of grapefruit oil components as potential novel efflux pump modulators in methicillin-resistant Staphylococcus aureus bacterial strains. Phytochemistry 2004, 65, 3021-3027. [CrossRef] [PubMed]

46. Lin, J.K.; Wu, T.S. Constituents of flowers of Murraya paniculata. J. Chin. Chem. Soc. 1994, 41, $213-216$. [CrossRef]

47. Youkwan, J.; Sutthivaiyakit, S.; Sutthivaiyakit, P. Citrusosides A-D and furanocoumarins with cholinesterase inhibitory activity from the fruit peels of Citrus hystrix. J. Nat. Prod. 2010, 73, 1879-1883. [CrossRef] [PubMed]

48. Hamdan, D.; El-Readi, M.Z.; Tahrani, A.; Herrmann, F.; Kaufmann, D.; Farrag, N.; El-Shazly, A.; Wink, M. Chemical composition and biological activity of Citrus jambhiri Lush. Food Chem. 2011, 127, $394-403$. [CrossRef] [PubMed]

49. Tan, X.Q.; Guo, L.J.; Chen, H.S.; Wu, L.S.; Kong, F.F. Study on the flavonoids constituents of Trachelospermum jasminoides. J. Chin. Med. Mater. 2010, 33, 58-60.

50. Matsubara, Y.; Kumamoto, H.; Iizuka, Y.; Murakami, T.; Okamoto, K.; Miyake, H.; Yokoi, K. Structure and hypertensive effect of flavonoid glycosides in Citrus unshiu peelings. Agric. Biol. Chem. 1985, 49, 909-914.

51. Donna, L.D.; Luca, G.D.; Mazzotti, F.; Napoli, A.; Salerno, R.; Taverna, D.; Sindona, G. Statin-like principles of bergamot fruit (Citrus bergamia): Isolation of 3-hydroxymethylglutaryl flavonoid glycosides. J. Nat. Prod. 2009, 72, 1352-1354. [CrossRef] [PubMed]

52. Lewin, G.; Maciuk, A.; Thoret, S.; Aubert, G.; Dubois, J.; Cresteil, T. Semisynthesis of natural flavones inhibiting tubulin polymerization, from hesperidin. J. Nat. Prod. 2010, 73, 702-706. [CrossRef] [PubMed]

53. Numonov, S.R.; Usmanova, S.K.; Aisa, H.A. A triterpenoid and flavonoids from Dracocephalum heterophyllum. Chem. Nat. Compd. 2013, 48, 1109-1110. [CrossRef]

54. Bowen, I.H.; Perera, K.P.W.C. Alkaloids, coumarins and flavonoids of Micromelum zeylanicum. Phytochemistry 1982, 21, 433-437. [CrossRef]

55. Akhtar, N.; Saleem, M.; Riaz, N.; Ali, M.S.; Yaqoob, A.; Nasim, F.; Jabbar, A. Isolation and characterization of the chemical constituents from Plumeria rubra. Phytochem. Lett. 2013, 6, 291-298. [CrossRef]

56. Ouyang, X.L.; Wei, L.X.; Fang, X.M.; Wang, H.S.; Pan, Y.M. Flavonoid constituents of Euonymus fortunei. Chem. Nat. Compd. 2013, 49, 428-431. [CrossRef]

57. Luyen, B.T.; Tai, B.H.; Thao, N.P.; Cha, J.Y.; Lee, H.Y.; Lee, Y.M.; Kim, Y.H. Anti-inflammatory components of Chrysanthemum indicum flowers. Bioorg. Med. Chem. Lett. 2015, 25, 266-269. [CrossRef] [PubMed]

58. Leu, Y.L.; Hwang, T.L.; Kuo, P.C.; Liou, K.P.; Huang, B.S.; Chen, G.F. Constituents from Vigna vexillata and their anti-inflammatory activity. Int. J. Mol. Sci. 2012, 13, 9754-9768. [CrossRef] [PubMed]

59. Louche, L.M.M.; Gaydou, E.M.; Lesage, J.C. Determination of phlorin as peel marker in orange (Citrus sinensis) fruits and juices. J. Agric. Food Chem. 1998, 46, 4193-4197. [CrossRef]

60. Sribuhom, T.; Sriphana, U.; Thongsri, Y.; Yenjai, C. Chemical constituents from the stems of Alyxia schlechteri. Phytochem. Lett. 2015, 11, 80-84. [CrossRef]

61. Ley, J.P.; Blings, M.; Paetz, S.; Krammer, G.E.; Bertram, H.J. New bitter-masking compounds: Hydroxylated benzoic acid amides of aromatic amines as structural analogues of homoeriodictyol. J. Agric. Food Chem. 2006, 54, 8574-8579. [CrossRef] [PubMed]

62. Takaya, Y.; Kondo, Y.; Furukawa, T.; Niwa, M. Antioxidant constituents of radish sprout (Kaiware-daikon), Raphanus sativus L. J. Agric. Food Chem. 2003, 51, 8061-8066. [CrossRef] [PubMed] 
63. Takahashi, H.; Kittaka, H.; Ikegami, S. Novel synthesis of enantiomerically pure natural inositols and their diastereoisomers. J. Org. Chem. 2001, 66, 2705-2716. [CrossRef] [PubMed]

64. Zhang, Q.; Shu, X.; Jing, F.; Wang, X.; Lin, C.; Luo, A. Preparative separation of alkaloids from Picrasma quassioides (D. Don) Benn. by conventional and pH-zone-refining countercurrent chromatography. Molecules 2014, 19, 8752-8761. [CrossRef] [PubMed]

65. Strehmel, N.; Böttcher, C.; Schmidt, S.; Scheel, D. Profiling of secondary metabolites in root exudates of Arabidopsis thaliana. Phytochemistry 2014, 108, 35-46. [CrossRef] [PubMed]

66. Yang, S.C.; Chung, P.J.; Ho, C.M.; Kuo, C.Y.; Hung, M.F.; Huang, Y.T.; Chang, W.Y.; Chang, Y.W.; Chan, K.H.; Hwang, T.L. Propofol inhibits superoxide production, elastase release, and chemotaxis in formyl peptide-activated human neutrophils by blocking formyl peptide receptor 1. J. Immunol. 2013, 190, 6511-6519. [CrossRef] [PubMed]

67. Yu, H.P.; Hsieh, P.W.; Chang, Y.J.; Chung, P.J.; Kuo, L.M.; Hwang, T.L. 2-(2-Fluorobenzamido) benzoate ethyl ester (EFB-1) inhibits superoxide production by human neutrophils and attenuates hemorrhagic shock-induced organ dysfunction in rats. Free Radic. Biol. Med. 2011, 50, 1737-1748. [CrossRef] [PubMed]

68. Wang, C.N.; Chi, C.W.; Lin, Y.L.; Chen, C.F.; Shiao, Y.J. The neuroprotective effects of phytoestrogens on amyloid $\beta$ protein-induced toxicity are mediated by abrogating the activation of caspase cascade in rat cortical neurons. J. Biol. Chem. 2001, 276, 5287-5295. [CrossRef] [PubMed]

Sample Availability: Samples of the purified compounds are available from the authors. 